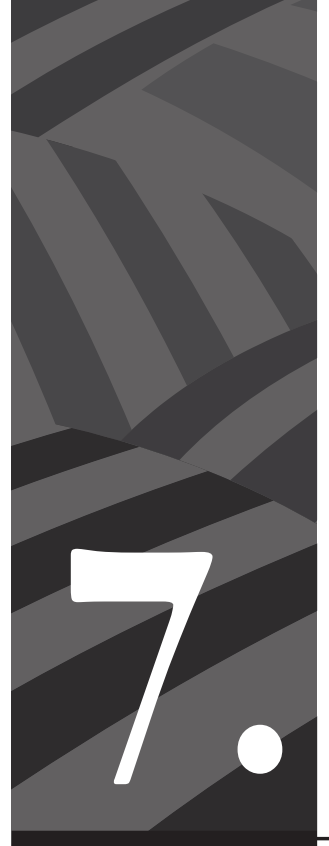

Prensa alternativa e izquierda: el caso de la revista Documentos Políticos en el periodo final de La Violencia 


\section{Prensa alternativa e izquierda: el caso de la revista Documentos Políticos en el periodo final de La Violencia ${ }^{1}$}

Por Lorena Guerrero ${ }^{2}$ y José Alejandro Cifuentes ${ }^{3}$

\section{Introducción}

L

a revista Documentos Políticos fue publicada por el Partido Comunis-

ta de Colombia entre 1956 y 1984. Aunque su función primaria era la Partido y su posición ante situaciones coyunturales, Documentos se convirtió poco a poco en una herramienta de prensa que permitía la difusión desde análisis de actualidad económica y política, temas históricos, problemas internacionales, y también arte y cultura. Es más, desde el número noventa y nueve, la publicación contenía reproducciones de trabajos de artistas plásticos, caricaturistas y fotógrafos nacionales e internacionales.

El presente artículo parte de la revisión del amplio trabajo de investigación y catalogación de esta publicación llevado a cabo por Beatriz Elisa Guerrero (2013). Dicha investigación nos ha permitido comprender la riqueza de Documentos Políticos como una fuente para la historia política y de la izquierda colombiana en la segunda mitad del siglo XX.

Artículo recibido en junio de 2106

Artículo aprobado en octubre de 2016.

2 Historiadora de la Pontificia Universidad Javeriana, estudiante de la Maestría en Geografía de la Universidad Nacional de Colombia.

3 Historiador de la Pontificia Universidad Javeriana, estudiante de la Maestría en Historia de la Universidad Nacional de Colombia. 
Pero, dado el espacio y lo extenso de la publicación, lo que presentamos a continuación son algunas reflexiones sobre la fundación de la revista. Documentos nos permite observar el esfuerzo del Partido Comunista por ganarse un espacio democrático en medio de la dictadura militar de Rojas Pinilla. Los primeros números de la revista son un testimonio del periodo de clandestinidad del Partido en medio del momento final de la Violencia.

\section{La dictadura y la ilegalización del comunismo}

Tras el golpe del 13 de junio de 1953, el general Gustavo Rojas Pinilla sube al poder; sin embargo, Rojas enfrentaba las consecuencias de su intento de gobernar sin los partidos tradicionales, mientras que los líderes conservadores y liberales fraguaban una alianza que les permitiría retomar el poder y la imagen de una democracia formal. Con la llegada del Frente Nacional, este nuevo periodo se entendería como un régimen de transición a la democracia tras un periodo de cuatro años de dictadura militar. Muy por el contrario, el análisis de este periodo nos enseña que el Frente Nacional implicó la monopolización del poder político por parte de liberales y conservadores, lo que condujo a la exclusión del sistema democrático de cualquier fuerza política disidente. Así pues, el Frente Nacional constituyó un nuevo periodo de antidemocracia que estuvo precedido por una década marcada por las dictaduras civiles conservadoras y una dictadura militar. Sin embargo, la oposición al régimen militar no se hizo esperar. Las fuertes represiones y castigos contra todo aquel que estuviese en contra de sus leyes y estatutos sería víctima de una justicia arbitraria. El Partido Comunista, siendo parte de la oposición, había sido condenado a la ilegalidad y se le había impuesto el delito de opinión ${ }^{4}$.

4 Debemos recordar que los comunistas ya habían sido víctimas de la persecución desde las dictaduras civiles conservadoras anteriores al régimen militar. 
A pesar de estos impedimentos, el Partido decide crear una revista de carácter teórico y de análisis político que hiciera frente al delito de opinión impuesto en el gobierno de Rojas Pinilla. La revista se constituiría como un elemento importante de la lucha política, sobre todo, porque desafiaría a la represión, difundiendo información con objetivos concretos. Así pues, la publicación sería un órgano de comunicación que guiaría la lucha contra el impuesto estatus de ilegalidad.

\section{Documentos políticos, nacimiento y consolidación}

La revista Documentos Políticos lanza su primer número en el mes de diciembre de 1956, mientras que el Partido Comunista se encontraba en la ilegalidad. Bajo la clandestinidad, Documentos saca sus primeros seis números impresos en mimeógrafo, y ello ante el peligro inminente de los atropellos por parte de las fuerzas represivas, puesto que una publicación era un abierto desacato a las disposiciones gubernamentales que impedían a los comunistas actuar en el escenario público colombiano. Por ello, Documentos Políticos, sería el apoyo y el eje central del Partido Comunista a la hora de enfrentar este periodo antidemocrático.

El decreto de ilegalización del comunismo incapacitaba al Partido para toda actividad pública y de participación política, además de que creaba de facto el delito de opinión. Pero los comunistas no se limitaron a quedarse de brazos cruzados. De ese espíritu de lucha nació la voluntad de crear una revista de análisis político y de actualidad, la cual bautizaron Documentos Políticos. Bajo la situación de ilegalidad que se les había impuesto, los comunistas concibieron una revista con el propósito formal de impulsar su tarea teórico-práctica, para formar una escuela nacional de cuadros, y donde se pudiesen expresar su plataforma política revolucionaria de liberación nacional y social por medio del trabajo intelectual.

La revista era una expresión de la lucha por la legalidad. En el XIX Pleno del Comité Central del Partido Comunista de Colombia, reunido en el mes de agosto de 1956, se planteó la reforma del programa del Parti- 
do. Allí se estipuló que el programa vigente en 1947 presentaba muchos errores y vacíos, porque básicamente el documento corría el riesgo de constituirse "en una colección de exigencias inmediatas y reformistas" (Comité Ejecutivo Central del Partido Comunista de Colombia, 1965,2).

La tarea de cambiar el programa era, según las directivas del Partido, de vital importancia para que dicho documento se convirtiera en una "brújula y [en] instrumento de nuestra lucha", ello con el fin de que el programa guiara al pueblo colombiano en la labor de "realizar la revolución democrática y popular en Colombia”(Comité Ejecutivo Central del Partido Comunista de Colombia, 1965,6). En este sentido, los comunistas comenzaron a enfrentar las posturas militaristas de las guerrillas activas, y a insistir en métodos pacíficos para alcanzar la revolución (Buenaventura, 1990). En medio de dichas posturas emitidas por el Comité Central, se hacía necesaria una publicación, que en principio sirviera para discutir lo relativo a la reforma del programa, donde aparecieran "las observaciones y discusiones de los temas, contenido y críticas de los temas, sobre él” (Buenaventura, 1990, 21-28).

Documentos Políticos se publicó inicialmente en el campo, en Tequendama. Su primera serie fue organizada por los dirigentes Hernando Hurtado, Martín Camargo y Álvaro Vásquez del Real. Los primeros números fueron elaborados en mimeógrafo, una herramienta rudimentaria pero que hacía que la producción de copias de la revista fuese mucho más barata y sencilla. Además, hay que tener en cuenta que, por lo estipulado en el Decreto 0434 de 1956, difícilmente los comunistas hubieran podido acceder a una imprenta para hacer un tiraje numeroso.

La intención de mantener una revista propia del Comité Central que sistematizara sus propias enseñanzas y determinaciones era una urgente necesidad, no daba espera a que se legalizara de nuevo al Partido. Esto queda claro en un texto de la contraportada de la primera entrega, allí se decía que Documentos Políticos “se publica por el Comité Central en cumplimiento de las decisiones del último Pleno [el 19²], el cual no 
hizo otra cosa que insistir en una antigua determinación del Partido. La necesidad de una revista del Comité Central se ha hecho en los últimos tiempos aún más urgente" (Comité Ejecutivo Central del Partido Comunista de Colombia, 1956, 1).

Este primer esfuerzo es resultado de la intensión de impulsar una publicación de una proporción considerable. De igual modo, es de importancia rescatar que poco tiempo después de aparecida Documentos, se inició la publicación del semanario Voz de la Democracia. Dicho periódico se constituyó como otra expresión más de la lucha por la legalidad, aunque no sea, tal como lo sostiene Nicolás Buenaventura (1990), la primera expresión por la legalidad , pues, como lo hemos visto, Documentos Políticos ya circulaba con el mismo objetivo.

El periódico se suma a la actividad intelectual y a la lucha por la democracia que los comunistas realizaban clandestinamente durante los últimos momentos de la dictadura militar. El 20 de julio de 1957 se publica el primer número de su periódico Voz de la Democracia, bajo la dirección del jurista Juan Francisco Mújica, y del director de Documentos Políticos, Álvaro Vásquez del Real. Hasta finalizar 1958 la publicación completó dieciocho ediciones, una por cada mes. En un comienzo, el periódico, al igual que la revista, tuvo una mayor difusión en las zonas agrarias. Ello debido a la fuerte censura que seguía existiendo en las ciudades durante el gobierno de la Junta Militar, que reemplazó a Rojas.

El hecho de que hubiese un tiraje de prensa a la par de su revista demuestra un grado de cohesión y organización en torno al trabajo intelectual. Los comunistas desde sus inicios plantearon un grupo orgánico de personas encargadas de darle vida a su labor publicista, involucrado desde el proceso de redacción hasta la difusión de sus publicaciones.

Con respecto a la constancia de la aparición de publicaciones comunistas en Colombia, Álvaro Vásquez del Real señala el papel vital que 
jugaron Documentos Políticos y el diario Voz de la Democracia, aparecidos hace más de medio siglo:

Yo creo que las dos publicaciones, digamos modelo del Partido han sido [la] revista Documentos y el periódico Voz. Porque tampoco antes de eso ningún periódico nuestro llegaba a más de 6 números. Con excepción de pronto de El Diario Popular que tuvo un periodo estable, pero también duró poco. Primero fue semanario, después fue diario, y después desapareció. Y los otros periódicos son bastante episódicos: Tierra, El Soviet. Y algunos regionales que hubo en Cali, en Barranquilla, y en Bogotá (Oviedo y Vásquez del Real, 2010, 32).

Sobre las experiencias del trabajo revolucionario durante la década de 1957, Documentos Políticos publica en su número dos un artículo titulado "Los problemas de la propaganda política”. Dicho artículo fue presentado como parte de la experiencia de un equipo de propagandistas del Partido Comunista Colombiano. Allí exponen cómo este equipo, dedicado a la propaganda del Partido, operó durante ocho años consecutivos. Es llamativo resaltar el trabajo realizado por este equipo de propagandistas, ya que, conociendo su carácter clandestino, contribuyeron en publicaciones de carácter semilegal, en periódicos, folletos, revistas, entre otros, y realizaron ediciones con una frecuencia casi diaria, y, a pesar de la persecución, nunca interrumpieron su labor.

El citado artículo, directamente enfocado en establecer los problemas de la propaganda política, fue dirigido a toda la oposición: escritores, editores, corresponsales, distribuidores, lectores organizados, sin importar el partido político o la clase social a la que pertenecieran. Por ser esta una publicación más amplia, la revista retoma algunos de sus elementos para hacer posible su difusión.

El tema de la propaganda se planteaba especialmente en una coyuntura como lo era la dictadura militar. Se señalaba que la propaganda era 
clave para lograr la unidad de las fuerzas opositoras al régimen, para coordinar dichas fuerzas, y así lograr congruencia de acción en contra del régimen represivo.

El artículo proponía una ruta para la elaboración de textos informativos y de propaganda. En primer lugar, debía recopilarse la información que la prensa oficial no estaba publicando, así como los sucesos que tenían que ver con la lucha del pueblo, que, a su vez, permitían denunciar los atropellos del régimen. Luego se debían agrupar los elementos y relacionarlos entre sí para difundirlos en un volante. Y así cuando a la gente le llegara nueva información, lo más seguro sería que

aún para el lector más desprevenido...le llegue la idea elemental de la lucha. Pero ya desde allí, es probable que el lector se interese por nuevas informaciones, si se organizan las cosas de manera que siga llegando a sus manos la propaganda, conversará inevitablemente con sus amigos sobre las noticias y terminará —en una buena parte de los casos- buscando los datos y la propaganda por su cuenta (Comité Ejecutivo Central del Partido Comunista de Colombia, 1957, 8).

Ya con este primer acercamiento, el individuo dejaría de sentirse ajeno a la situación y pasaría a ser un participante en la lucha. Para completar la estructura, hacía falta el elemento organizativo, ya que "el papel de la propaganda es empujar y conducir a la acción coordinada, a la organización de la lucha" (Comité Ejecutivo Central del Partido Comunista de Colombia, 1957, 8). Ello como principal referente a la hora de convertir en efectiva resistencia la oposición al régimen. Los autores del texto también explican la circulación de la propaganda, señalando que la noticia se transforma en una verdadera arma si se escribe en el papel y se hace circular:

la gente sabe que el papel no se escribe él mismo ni camina solo. Al recibirlo el obrero o el estudiante o el profesional, tiene la seguridad de que detrás del escrito hay alguien que actúa. El papel da testimonio de que existe 
una organización, o sea una fuerza. Entonces se siente empujado por esa fuerza y desea actuar a la vez. He allí la función de la propaganda (Comité Ejecutivo Central del Partido Comunista de Colombia, 1957, 9).

Este elemento hay que tenerlo bien presente, pues en un momento en el que el régimen había decretado el delito de opinión a todo aquel que le hiciera oposición se hizo necesaria una abundante y ágil propaganda de toda índole. Dicen los autores, que era entonces de suma importancia construir "un frente de lucha capaz de derrocar a corto plazo el poder de la autocracia”. Pero este frente debía apuntar a una tarea más trascedente y difícil, a saber: “construir un nuevo poder, el poder democrático, auténticamente popular” (Comité Ejecutivo Central del Partido Comunista de Colombia, 1957, 9). En ese frente de lucha se basó el Partido Comunista para contrarrestar al régimen, si bien se dio la pelea, no fue tarea fácil, especialmente debido a que el régimen militar "se [había] empeñado en destruir o amordazar todos los periódicos más o menos independientes, no importa las clases a que pertenezcan" (Comité Ejecutivo Central del Partido Comunista de Colombia, 1957, 9.).

La persecución era feroz, por ello los impulsores de la prensa opositora tuvieron que actuar de manera furtiva. Debido a lo anterior, muchos escritores y propagandistas fueron tildados de bandoleros o delincuentes, fueron encarcelados, recluidos o asesinados. Pese a esta situación, el artículo advertía que no se debía asumir que la propaganda "clandestina”, al ser ilegal, debía ser agresiva y carente de contenido. El hecho de que fuera "clandestina” no era motivo para el uso de

palabras atrevidas y subidas de tono [ya que] así, descuidan el estilo y el análisis en la propaganda y se preocupan solo por decir en ella, como por desquite, todas las frases que no cabrían en la propaganda supervigilada por el régimen (Comité Ejecutivo Central del Partido Comunista de Colombia, 1957, 10-11). 
Todo lo contrario, muchos documentos escritos con destino a la prensa censurada no pudieron ser publicados por motivos de descalificación oficial, por tanto, pasaron a ser textos clandestinos, que la gente se encargó de reproducir y difundir. El hecho de que sea tildado de clandestino, nos dicen los autores de Documentos, se debe a que no quieren que se reproduzca la verdad y por ello se intenta borrarla a como dé lugar. Por ello, la información que se intentaba trasmitir, al ir dirigida al pueblo, tenía que ser sobre el atropello diario, aquel que se expresaba en los bajos salarios, en las alzas de precios, en el recorte de las libertades, etcétera. Así, según las declaraciones del Comité Ejecutivo Central del Partido Comunista "la única garantía para la larga vida de un órgano de propaganda popular es un sistema que permita recibir regularmente, sin interrupciones, las noticias y opiniones de las gentes a las cuales va dirigido" (Comité Ejecutivo Central del Partido Comunista de Colombia, 1957, 14).

Es necesario recordar que la actividad intelectual del Partido Comunista, plasmada en Documentos Políticos, tomó forma en medio de los difíciles momentos que atravesó el país en la década de 1950. Los gobiernos autoritarios conservadores de 1946-1953, y luego la dictadura militar de Rojas Pinilla, como hemos visto, buscaron silenciar a la oposición, entre ella a los comunistas. Ante las restricciones de las libertades civiles y la creciente violencia, el Partido Comunista no se quedó impávido. Por el contrario, fue un agente político activo que adoptó una postura y una línea de acción, desde la participación en los grupos armados que resistían en el campo a la violencia oficial y conservadora, hasta la actividad propagandística clandestina, acciones estas que también afectaron el proceso de conformación de su revista.

\section{Documentos Políticos y el escenario internacional: XX Congreso del PCUS}

Documentos Políticos fue a su vez una publicación que debía difundir los principales debates y temas de actualidad del escenario internacio- 
nal. Esta tarea se planteó en 1956, un momento de inflexión pues se realizó el XX Congreso del Partido Comunista de la Unión Soviética, el primero organizado tras la muerte de Stalin. Este evento tuvo un impacto en el movimiento comunista internacional. En este Congreso, a cargo de Nikita. S. Jruschov, se dio la denuncia del régimen de Stalin. Aunque al discurso de Jruschov donde se criticaba al accionar de Stalin, no se permitió la asistencia de los delegados extranjeros, el Congreso inauguró la lucha contra el culto a la personalidad (Eric Hobsbawm, 1981). El Partido Comunista de Colombia comenzó la discusión de problemas propuestos en el XX Congreso soviético dentro de las condiciones nacionales que estos estaban viviendo. Pronto, Documentos Políticos se convirtió en plataforma de difusión de estos problemas.

En el primer número de la revista, el Comité Ejecutivo Central del Partido Comunista de Colombia explicó que uno de los propósitos de Documentos era realizar:

un positivo aporte al estudio de las experiencias internacionales, al conocimiento de los problemas nacionales y a la profundización de las cuestiones que plantea la construcción de nuestro Partido. Teniendo en cuenta que hoy discutimos un proyecto de Programa del Partido y nuevos estatutos, la revista recogerá los aportes del Partido en relación con la elaboración de ambos documentos. Igualmente, en las discusiones de nuestro Partido acerca de los aspectos que ha llevado a primer plano el XX Congreso del PCUS, nuestra Revista debe ser una amplia tribuna que refleje esas discusiones (Comité Ejecutivo Central del Partido Comunista de Colombia, 1957, contraportada).

El Partido se inscribía en un movimiento comunista internacional. Aunque dicho movimiento ya no era dirigido desde Moscú por la Komintern, disuelta en la década de 1940, en Colombia el Partido sí estaba atento a lo que ocurriera en el seno de los partidos comunistas y obreros más importantes del mundo. Las discusiones que se dieran en el seno del 
Partido Comunista soviético, iban a repercutir indiscutiblemente en este movimiento internacional. Además, como lo señala Eric Hobsbawm (1981), con la llegada de Mao al Poder, la China comunista comenzaba a desafiar el liderazgo soviético, lo cual llevó a que las discusiones del PCUS en 1956 tuvieran una mayor trascendencia.

En el primer número de Documentos Políticos se publicaron varios extractos de los textos de las resoluciones tomadas durante el XX Congreso del PCUS, sobre todo, las relacionadas con el culto a la personalidad (Comité Ejecutivo Central del Partido Comunista de Colombia, 1956). De esta forma, Documentos Políticos fue planteada desde el principio como una publicación internacionalista, una que supliera al desparecido semanario Por una Paz duradera, por una Democracia Popular, publicado por la Kominform:

Al decidirse por los respectivos Partidos Comunistas, la cesación de las funciones del Buro de Información de los Partidos Comunistas y Obreros y dejar de aparecer el semanario (sic.) POR UNA PAZ DURADERA, POR UNA DEMOCRACIA POPULAR” [...] se ha hecho más imperiosa una publicación del Partido que, de una parte, recoja los mejores documentos del movimiento comunista internacional, y de otra, sirva de órgano de los propios documentos de nuestro Partido y de los estudios que los comunistas colombianos consideren más importantes en relación con los problemas del pueblo y del movimiento revolucionario nacional (Comité Ejecutivo Central del Partido Comunista de Colombia, 1957, contraportada).

\section{Conclusiones}

Como señalábamos, con la instauración del Frente Nacional, y tras la llegada a la presidente de Alberto Lleras, Documentos Políticos conseguiría una licencia oficial para ser publicada. Este nuevo régimen político, aparentemente democrático, significaba la exclusión de cualquier voz disidente del bipartidismo. A su vez, se inició una nueva fase del conflicto desatado desde la década de 1940. En ese contexto, 
la revista de los comunistas tendría nuevos retos: al mismo tiempo que debía ampliar sus contenidos, debía jugar también un papel importante en el esfuerzo de "construir una nueva cultura".

Veremos en la revista la participación de artistas como Fernando Oramas u Olivia Miranda, y de investigadores de envergadura como el urbanista Jacques Aprile. Pero lo que importa destacar aquí es que Documentos fue resultado del sueño de un grupo de intelectuales orgánicos que buscaban encauzar los esfuerzos de oposición a un régimen político excluyente y violento.

La revista es una expresión política del Partido Comunista en un periodo complejo de la historia del país, la Violencia. Es de resaltar dicha situación, pues durante el ambiente hostil vivido bajo el gobierno de Rojas Pinilla cualquier alusión al comunismo internacional era castigada de manera arbitraria por la justicia militar. Y eso no es de extrañar, porque en Occidente se vivía una dura campaña anticomunista liderada por los órganos de propaganda e inteligencia norteamericanos (Stonor, 2013 y Hobsbawm, 2003).

Finalmente, es importante afirmar que Documentos Políticos es aún una fuente por explorar para la historia de las izquierdas en Colombia. 


\section{Bibliografía}

Buenaventura, N. (1990). Cuadernos de Historia del PCC, Cuaderno II, "El origen del Frente Nacional (1957-58)” Bogotá: Editorial Ceis-Inedo.

Bushnell, D. (2009). Colombia una nación a pesar de sí misma. Bogotá: Editorial Planeta.

Cajas Sarria, M. (2008). El control judicial a la reforma constitucional. Cali: Universidad Icesi.

Comité Central del Partido Comunista de Colombia (1953, agosto 11). Resolución política. (Mimeógrafo)

Comité Central del Partido Comunista de Colombia (1960). Treinta años de lucha del partido Comunista de Colombia. Bogotá: Ediciones Paz y Socialismo.

Comité Ejecutivo Central del Partido Comunista de Colombia (1956). El programa. Documentos Políticos. Órgano central del Partido Comunista de Colombia, 1.

Comité Ejecutivo Central del Partido Comunista de Colombia (1957). Los problemas de la propaganda política Documentos Políticos. Órgano central del Partido Comunista de Colombia, 2.

Comité Ejecutivo Central del Partido Comunista de Colombia (s. f.). Documentos Políticos. Contra portada.

Galvis, S. y Donadio, A. (1988). El jefe supremo. Rojas Pinilla en la Violencia y el poder. Bogotá: Planeta.

Gramsci A. (1999). Cuadernos de la cárcel, tomo 4. México: Ediciones Era.

Guerrero Mojica, B. (2013). El trabajo intelectual y político del Partido Comunista de Colombia: documentos políticos 1956-1963 [Tesis de pregrado en Historia]. Pontificia Universidad Javeriana, Bogotá.

Hartlyn, J. (1993). La política del régimen de coalición. La experiencia del Frente Nacional en Colombia. Bogotá: Tercer Mundo Editores, Ediciones Uniandes.

Henderson, J. (2006). La modernización en Colombia: los años de Laureano Gómez, 1889-1965. Medellín: Universidad de Antioquia. 
Hobsbawm, E. (2003). Años interesantes, una vida en el siglo XX. Barcelona: Editorial Crítica.

Hobsbawm, E. (2010). Historia del Siglo XX. Barcelona: Editorial Crítica.

Marcou, L. (1981). El movimiento comunista internacional desde 1945. Bogotá: Siglo XXI Editores.

Oviedo Hernández, Á. y Vásquez del Real, Á. (2010). Memoria y luchas sociales. Bogotá: Ediciones Izquierda Viva.

Oviedo, Á. (2009). Sindicalismo colombiano. Iglesia e ideario católico 19451957. Quito: Corporación Editora Nacional, Universidad Andina Simón Bolívar.

Sáenz Rovner, E. (2001). La misión del Banco Mundial en Colombia, el gobierno de Laureano Gómez (1950-1951) y la Asociación Nacional de Industriales (Andi). Cuadernos de Economía, 35.

Sáenz Rovner, E. (2002). Colombia años 50: industriales, política y diplomacia. Bogotá: Universidad Nacional de Colombia.

Sánchez, G. y Meertens, D. (2006). Bandoleros, gamonales y campesinos. El caso de la Violencia en Colombia. Bogotá: Punto de Lectura.

Sánchez, G. y Meertens, D. (2013, enero-abril). Tierra y violencia. El desarrollo desigual de las regiones. Análisis Político, (6). Recuperado de http://www. plataformademocratica.org/Publicacoes/4812.pdf

Stonor Saunders, F. (2013). La CIA y la Guerra Fría cultural. Bogotá: Debate.

Tirado Mejía, Á. (1989). El gobierno de Laureano Gómez, de la dictadura civil a la dictadura militar. En Á. Tirado Mejía (ed.). Nueva Historia de Colombia, vol. 2. Bogotá: Planeta.

Urán, C. (1983). Rojas y la manipulación del poder. Bogotá: Carlos Valencia Editores.

Vieira, G. (1953, agosto). Informe del Secretario General al XVI Pleno del Comité Central (Mimeógrafo). 